\title{
Combination Chemotherapy in Cancer: Principles, Evaluation and Drug Delivery Strategies
}

\author{
Ana Catarina Pinto ${ }^{1}$, João Nuno Moreira ${ }^{2,3}$ and Sérgio Simões ${ }^{1,2,3}$ \\ ${ }^{1}$ Bluepharma, Indústria Farmacêutica S.A., S. Martinho do Bispo, Coimbra \\ ${ }^{2}$ Laboratory of Pharmaceutical Technology, Faculty of Pharmacy, \\ University of Coimbra, Coimbra \\ ${ }^{3}$ Center for Neurosciences and Cell Biology, University of Coimbra, Coimbra \\ Portugal
}

\section{Introduction}

Cancer is a major public health problem since it is the second leading cause of illness-related death, only exceeded by heart disease (American Cancer Society [ACS], (2010)). Cancer results from structural and quantitative alterations in molecules that control different aspects of cell behavior. Genetic alterations probably represent the most common mechanisms for molecular changes that cause the development and progression of cancer (Dong, 2006). Great efforts have been made to identify common genetic modifications and the underlying target genes. Genetic alterations can be inherited, as in hereditary cancers, or induced by endogenous and exogenous carcinogenic factors as in most sporadic cancers (Dong, 2006). The six essential changes in cell physiology suggested to collectively dictate malignant growth are self-sufficiency in growth signals, insensitivity to anti-growth signals, tissue invasion and metastasis, limitless replicative potential, sustained angiogenesis and evading apoptosis (Hanahan \& Weinberg, 2000).

Chemotherapeutic agents used in current clinical practice have played a significant role in reducing mortality/morbidity and in increasing patient's quality of life (Suggit \& Bibby, 2005). Despite the recent advances in early diagnosis and in clinical protocols for cancer treatment, the development of antineoplastic agents that combine efficacy, safety and convenience for the patient remains a great challenge (Ismael et al., 2008).

Most anticancer drugs have narrow therapeutic index, develop multidrug resistance (MDR) and present unspecific biodistribution upon intravenous administration leading to unacceptable side effects to healthy tissues, mainly bone marrow and gastrointestinal tract. These limitations of conventional chemotherapeutic strategies frequently result in suboptimal dosing, treatment delay or discontinuance and reduced patient compliance to therapy (Ismael et al., 2008).

\section{Combination chemotherapy}

\subsection{Principles and advantages}

Combination therapy has been the standard of care, especially in cancer treatment, since it is a rationale strategy to increase response and tolerability and to decrease resistance. 
Currently, there is a growing interest in combining anticancer drugs aiming at maximizing efficacy while minimizing systemic toxicity through the delivery of lower drug doses (Mayer \& Janoff, 2007; Ramsey et al., 2005; Zoli et al., 2001).

The fundamentals of combination chemotherapy development have remained largely unchanged over the last decades. The general principles have been to: i) use drugs with nonoverlapping toxicities so that each drug can be administered at near-maximal dose; ii) combine agents with different mechanisms of action and minimal cross-resistance in order to inhibit the emergence of broad spectrum drug resistance; iii) preferentially use drugs with proven activity as single drugs and iv) administer the combination at early stage disease and at a schedule with a minimal treatment-free period between cycles but still allowing the recovery of sensitive target tissues (Mayer \& Janoff, 2007; Harasym et al, 2007; Ramsey et al., 2005; Zoli et al., 2001). The advantages attributed to combination chemotherapy include improved patient compliance due to the reduced number of administrations, emergence of additive or synergistic interaction effects, ability to overcome or delay MDR and reduction of drug dose with consequent diminishing of toxicity to healthy tissues (Chou, 2010, 2006; Ramsey et al., 2005).

As an example, multimodal combination treatments for hormone refractory prostate cancer (HRPC) have gained support in the clinical setting over the last decade (De la Taille et al., 2001). Given the complexity, heterogeneity, resistance and recurrence features of prostate cancer, rationally-designed drug combinations are necessary to achieve significant therapeutic progress (Armstrong \& Carducci, 2006).

\subsection{Preclinical vs. clinical drug combination studies}

The majority of clinical protocols for cancer combination therapies are mainly obtained empirically, in the absence of supporting experimental data, or based on results derived from retrospective analysis of clinical trials (Zoli et al, 2001; Goldie, 2001). These studies investigate the sequencing and scheduling of drugs rather than determining the optimal drug interactions. Information obtained from clinical protocols is valuable, but is timeconsuming, expensive and does not provide data on the biochemical and molecular mechanisms of drug interaction at cellular level resulted from combined treatments (Zoli et al., 2001). It is very difficult to determine whether drug combinations are acting in a synergistic, additive or antagonistic fashion in cancer patients. Ultimately, one can only determine whether a new combination provides a statistically significant increase in a specific end point such as response rate, time to progression or survival (Mayer, 2007).

Preclinical drug interaction studies allow a more rational design of clinical combination chemotherapy protocols, which are generally based on the empiric assumption that maximal efficacy will be achieved by co-administering each drug at their maximum tolerated doses (MTDs) (Mayer \& Janoff, 2007; Harasym et al., 2007; Mayer et al., 2006). This "more-is-better" philosophy applied to anticancer combinations may result in higher toxicity with minimal therapeutic benefit due to concentration-dependent drug interactions (Mayer et al, 2006; Ramsey et al., 2005). Undoubtedly, there are several molecular and pharmacological factors that determine the effectiveness of drug combinations. A rationallydesigned fixed drug combination is required since certain drug ratios can be synergistic, while others are additive or even antagonistic (Mayer \& Janoff, 2007; Mayer et al., 2006).

The design of preclinical drug combination studies on established cell lines, primary cell cultures or animal models has to take into account several factors such as drug 
concentration, exposure time, drug administration schedule and analytic method for evaluating the drug interaction (Zoli et al., 2001).

\subsection{In vitro vs. in vivo drug combination studies}

Evaluation of drug ratio-dependent effects in combination chemotherapy is frequently conducted in cell culture systems. During the course of the experiment, concentration and duration of administered drug(s) can be tightly controlled and the inhibition of tumor cell growth can be easily measured (Mayer \& Janoff, 2007; Harasym et al., 2007; Chou et al., 2006). For the last two decades, in vitro experimentation with tumor-derived cell lines has been the most important resource for investigating molecular mechanisms of cancer pathogenesis (Mitchell et al., 2000). There are a number of advantages associated with the use of cell culture systems, e.g. availability of a wide range of human tumor cell lines, flexibility of culture conditions and easiness of protein/nucleic acid quantification (Harasym et al., 2007). Additionally, in vitro tests not only evaluate antiproliferative effects of tested drugs but also assess interference on cell cycle, induction of apoptosis and existence of molecular or biochemical interactions (Zoli et al., 2001).

Unfortunately, cell culture studies are of limited usefulness because the conditions are artificial, do not reflect the heterogeneity of clinical malignant disease and, hence, are unable to evaluate the therapeutic index (Budman et al., 2002). Unlike in vitro studies where drug concentration is relatively constant, in vivo models represents a dynamic system, where drug molecules undergo absorption, distribution, metabolism and elimination, thus leading to plasma drug concentration changes over time (Merlin, 1994). Nevertheless, when compared to in vitro studies, the determination of synergism or antagonism in vivo using animal models is more time consuming, more expensive and greater variability in measurements occurs. Therefore, in vivo drug combination studies are usually carried out, only for selected drugs, after in vitro evaluation and before clinical trials (Chou, 2010, 2006).

\section{Drug interaction effects in combination chemotherapy}

\subsection{Definition and in vitro quantitative evaluation}

A drug combination can result in synergistic, antagonistic or additive interaction effects at different concentration ratios. Synergy, additivity and antagonism are defined as the interaction between two or more components such that the combined effect is superior, equal or inferior, respectively, to the expected sum of individual effects. Additivity means that each constituent contributes to the effect in accordance with its own potency (Chou, 2006; Merlin, 1994).

Systematic screening analysis of drug combinations can identify additive or synergistic relationships previously unrecognized (Mayer \& Janoff, 2007). In vitro synergistic activity is strongly dependent on drug:drug ratio and that dependence has profound implications on clinical application, since in vivo activity relies on the maintenance of those therapeutic ratios at the disease site (Mayer \& Janoff, 2007; Harasym et al., 2007; Mayer et al., 2006). Therefore, in order to achieve maximal therapeutic efficacy in vivo, dosing schedule is essential to allow exposure of tumor cells to defined drug concentrations (Zhao et al., 2008).

Several methods for the quantitative evaluation of drug-combined interaction effects have been used and were comparatively reviewed elsewhere (Zoli et al., 2001; Merlin, 1994). A brief description of the principles and limitations of the different methods is compiled in Table 1. However, in the present book chapter only the median effect analysis is extensively reviewed in the next section. 


\begin{tabular}{|c|c|c|c|}
\hline Method & Author & Principle & Limitations \\
\hline $\begin{array}{l}\text { Fractional } \\
\text { product }\end{array}$ & $\begin{array}{l}\text { Webb } \\
(1963)\end{array}$ & $\begin{array}{l}\text { Summation of the effects of } \\
\text { two inhibitors is expressed by } \\
\text { the product of the fractional } \\
\text { activities }\end{array}$ & $\begin{array}{l}\text { Method does not take into account the } \\
\text { possible sigmoidicity of the dose } \\
\text { response curves }(\mathrm{m}>1 \text { or } \mathrm{m}<1) \text { and is } \\
\text { not applicable in the case of two } \\
\text { mutually exclusive drugs or second-order } \\
\text { mutually non-exclusive drugs }\end{array}$ \\
\hline $\begin{array}{l}\text { Classical } \\
\text { isobologram }\end{array}$ & $\begin{array}{l}\text { Loewe } \\
(1957)\end{array}$ & $\begin{array}{l}\text { Lines join doses or dose- } \\
\text { combinations exerting the } \\
\text { same effect (iso-effect) }\end{array}$ & \multirow{2}{*}{$\begin{array}{l}\text { Method requires a large number of data } \\
\text { points, has poor computer software, the } \\
\text { statistical approach is incomplete and } \\
\text { only two-drug combinations can be } \\
\text { evaluated. Method is not applicable in } \\
\text { the case of two mutually non-exclusive } \\
\text { drugs }\end{array}$} \\
\hline $\begin{array}{l}\text { Isobologram } \\
\text { modified }\end{array}$ & $\begin{array}{l}\text { Stell and } \\
\text { Peckham } \\
\text { (1979) }\end{array}$ & $\begin{array}{l}\text { Envelope of additivity: a } \\
\text { region delimited by } \\
\text { confidence limits in which the } \\
\text { cytotoxic agents are not } \\
\text { significantly interacting }\end{array}$ & \\
\hline $\begin{array}{l}\text { Median effect } \\
\text { analysis }\end{array}$ & $\begin{array}{l}\text { Chou and } \\
\text { Talalay } \\
(1984)\end{array}$ & $\begin{array}{l}\text { Enzyme kinetic system: mass } \\
\text { action law, Michaelis-Menten } \\
\text { and Hill equations }\end{array}$ & $\begin{array}{l}\text { Method should not be applied when the } \\
\text { dose-response curves are not sigmoidal } \\
\text { because of the difficulty of applying } \\
\text { linear regression analysis }\end{array}$ \\
\hline $\begin{array}{l}\text { Three- } \\
\text { dimensional }\end{array}$ & $\begin{array}{c}\text { Fraser (1972) } \\
\text { Carter and } \\
\text { Wampler (1986) } \\
\text { Kanzawa (1997) }\end{array}$ & $\begin{array}{l}\text { Michaelis-Menten equations } \\
\text { Median effect principle }\end{array}$ & $\begin{array}{l}\text { Model requires several mathematical } \\
\text { functions and software for each different } \\
\text { type of response surface. The complex } \\
\text { execution prevents it from being widely } \\
\text { used in preclinical studies }\end{array}$ \\
\hline
\end{tabular}

Table 1. Methods for the quantitative evaluation of drug combination effects. Data was adapted and compiled from several literature references (Chou, 2006, 1994; Chou \& Talalay, 1984; Zoli et al., 2001; Merlin, 1994).

\subsection{The median effect analysis}

By far the most prevalent method used for quantitative evaluation of drug combinations is the median effect analysis proposed by Chou and Talalay (Chou, 2010, 2006, 1994; Chou \& Talalay, 1984). The fundamental equations of this method were derived from mass action enzyme kinetic models, previously established for enzyme-substrate interactions and then extended to multiple drug combinations (Chou, 1976). The equations underlying the median effect principle can be considered as a generalized form including the concepts of fractional product and isobologram analysis (Table 1) (Merlin, 1994; Chou \& Talalay, 1984).

Regardless of the shape of the dose-effect curve or the drug mechanism of action, the median effect equation correlates drug dose and corresponding effect (cell growth inhibition) and is given by:

$$
\mathrm{f}_{\mathrm{a}} / \mathrm{f}_{\mathrm{u}}=\left(\mathrm{D} / \mathrm{D}_{\mathrm{m}}\right)^{\mathrm{m}}
$$

Where $f_{a}$ and $f_{u}$ are the fractions of cells affected and unaffected, respectively, by a dose (D); $\mathrm{D}_{\mathrm{m}}$ is the dose causing the median effect and $m$ the coefficient traducing the shape of the dose effect curve $(\mathrm{m}=1,>1$ and $<1$, indicate hyperbolic, sigmoidal and negative sigmoidal, 
respectively). The $m$ and $D_{m}$ parameters are easily determined from the median effect plot since they correspond to the slope and to the antilog of the $\mathrm{x}$-intercept, respectively (Chou 2006, 1994; Chou et al. 1994). When $\mathrm{m}$ and $\mathrm{D}_{\mathrm{m}}$ are determined, the entire dose-effect relationship is described since for a given dose (D) it is possible to calculate the effect $\left(f_{a}\right)$ and vice-versa (Chou, 2010, 1994). Application of equation 1 allows the linearization of hyperbolic $(m=1)$ as well as sigmoidal curves $(m \neq 1)$ which are often encountered in chemotherapy treatment data (Merlin, 1994; Chou \& Talalay, 1984). Plotting $x=\log (\mathrm{D})$ vs. $\mathrm{y}$ $=\log \left(\mathrm{f}_{\mathrm{a}} / \mathrm{f}_{\mathrm{u}}\right)$ based on the logarithm form of equation 1 is called the median effect plot (Chou, 2010, 2006) (Fig. 1).
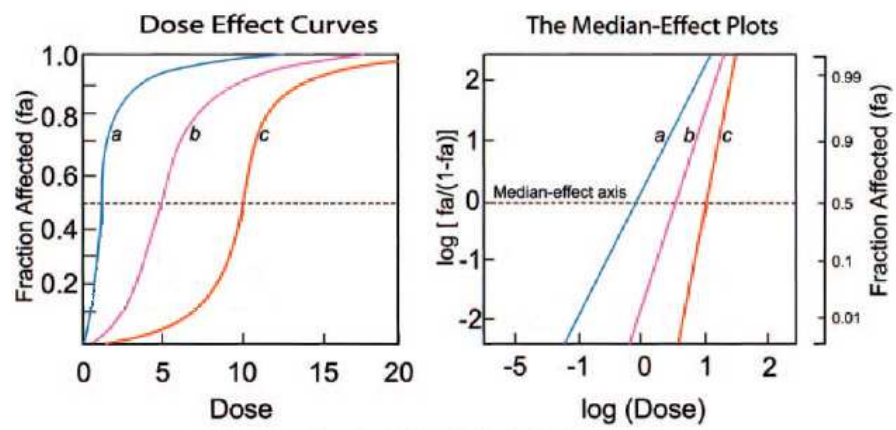

Fig. 1. Graphical representations executed in the median effect analysis method. Three sigmoidal dose-effect curves $(a, b, c)$ (left graph) and respective transformation into the corresponding linear forms by the median effect plot (right graph), where $y=\log (\mathrm{fa} / \mathrm{fu}) \mathrm{vs}$. $x=\log (\mathrm{D})$. Adapted from reference (Chou, 2006).

The conformity of the data to the median effect principle can be readily manifested by the linear correlation coefficient $(r)$ of the plot, in which $r=1$ indicates perfect conformity (Chou, 2010, 2006, 1994). The fractional effect associated with a range of concentrations is determined for each individual drug and for their combination. The median effect plot gives parallel lines if the drugs have the same or similar modes of action and the effects are then considered mutually exclusive; if the plots for single drugs are parallel but the mixture plot is concave upward with the tendency to intersect the plot of the more potent drug, the drugs act independently and their effects are considered mutually non-exclusive (Chou \& Talalay, 1984).

The combination index (CI) quantitatively evaluates the nature of drug interaction and is defined by the following equation:

$$
\mathrm{CI}=\frac{(D)_{1}}{\left(D_{x}\right)_{1}}+\frac{(D)_{2}}{\left(D_{x}\right)_{2}}+\alpha \frac{(D)_{1}(D)_{2}}{\left(D_{x}\right)_{1}\left(D_{x}\right)_{2}}
$$

Where $\alpha=0$ and $\alpha=1$, for drugs with mutually exclusive or non-exclusive mechanisms of action, respectively (Chou, 2010, 2006, 1994; Chou \& Talalay, 1984). Denominators $\left(D_{x}\right)_{1}$ and $\left(D_{x}\right)_{2}$ are drug doses required to achieve a given effect level $\left(f_{a}\right)$. Numerators $(D)_{1}$ and $(D)_{2}$ are doses of each drug in a given mixture which originates the same $f_{a}$. For three-drug combinations, a third term $(D)_{3} /\left(D_{x}\right)_{3}$ is added to equation 2 . A plot of $\mathrm{CI}$ as a function of 
effect level $\left(f_{a}\right)$ is represented in Fig. 2. CI values reflect synergism, additivity or antagonism when inferior, equal or superior to 1 , respectively.

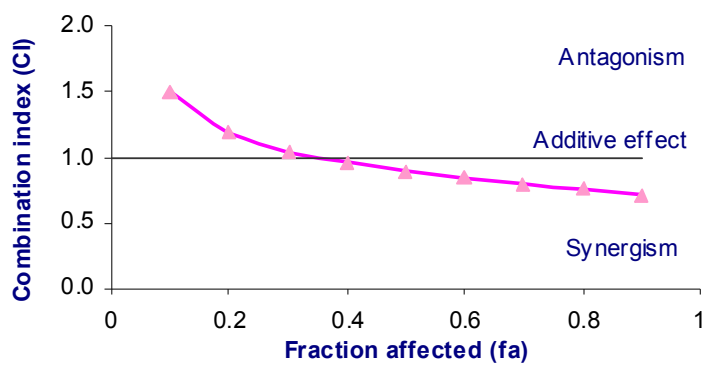

Fig. 2. Graphical representation of an exemplificative CI - fa plot. Combination index $(\mathrm{CI})<$ $1,=1,>1$ indicate synergism, additivity and antagonism, respectively.

If the nature of drug mechanisms is not clear, the authors of the method suggest that CI value must be determined by both mutually exclusive $(\alpha=0)$ and mutually non-exclusive ( $\alpha$ $=1$ ) assumptions. The later approach is more conservative as the addition of a third term in equation 2 results in higher CI values than the former one (Chou, 2006, 1994, Chou \& Talalay, 1984). Even though the CI value can be expressed for any effect level, the most accurate determination is for $f_{a}=0.5$ since the median effect plot may be unreliable at the extremes as it represents a linear approximation of a non-linear function (Kreis et al., 2001). The median effect analysis is a simple quantitative method that takes into account not only the potency $\left(\mathrm{D}_{\mathrm{m}}\right)$ of each drug and of their combination but also the shape (hyperbolic or sigmoidal) of their dose-effect curves (Chou, 1994; Chou et al., 1994). Furthermore, this method evaluates interaction effects at different drug ratios, at different effect levels and up to three agents can be evaluated simultaneously (Chou et al., 1994; Chou \& Talalay, 1984). It is recommended that an experiment should be carried out using a constant equipotency ratio (e.g. $\left.\left(\mathrm{IC}_{50}\right)_{1} /\left(\mathrm{IC}_{50}\right)_{2}\right)$ so that the effect contribution of each drug to the combination can be roughly equal (Chou, 2010, 2006; Chou \& Talalay, 1984). When evaluating anticancer drug combinations, the dose range administered must be wide enough to allow extrapolation of the results up to high levels of activity, i.e. $f_{a} \geq 0.5$, owing to the fact that tumor growth inhibition below that level is not clinically meaningful (Chou, 2010; Harasym et al., 2007; Merlin, 1994).

Dose reduction index (DRI) is a measure of how many folds the dose of a combined drug may be reduced at a given effect level as compared to the dose of the drug alone (Chou, 2006; Mayer et al., 2006). DRI is an important parameter in clinical practice because a favorable value $(>1)$ may lead to reduced systemic toxicity toward healthy tissues while maintaining therapeutic efficacy (Chou, 2010, 2006, 1998, 1994; Chou \& Talalay, 1984).

\section{Nanoparticles as drug delivery systems}

In face of the difficulties and high costs inherent to the development of new therapeutic molecules, the strategy of most pharmaceutical companies seems to rely on the optimization of the existing drugs, namely those characterized by a low therapeutic index. In particular, 
the application of nanotechnology-based drug delivery systems, such as liposomes, to cancer chemotherapy has been an exciting and promising area of research and constitutes an important ongoing effort to improve specificity and efficacy of anticancer drugs.

\subsection{Different types of nanoparticles}

Several drugs have physical and biological properties which hinder their clinical applicability, namely poor water solubility, rapid metabolism, instability under physiological conditions, unfavorable pharmacokinetics and unspecific biodistribution to healthy tissues (Allen, 1998). Particularly, in the case of anticancer drugs, such features ultimately lead to inadequate delivery of effective therapeutic drug concentrations to tumor tissue and/or unacceptable toxic effects (Andresen et al., 2005; Cattel et al., 2003). Therefore, it is crucial to develop nanotechnology-based platforms (lipid or polymer-based nanocarriers such as liposomes, micelles, polymeric nanoparticles or dendrimers) to promote and control delivery of some anticancer drugs to tumors (Devalapally et al., 2007; Peer et al., 2007; Dutta, 2007) (Fig. 3).

Nanoparticles with medical applications differ in terms of structure, size and composition, thus resulting in different characteristics, namely drug loading capacity, physical stability and targeted delivery ability (Haley \& Frenkel, 2008). It is beyond the scope of this chapter to review the current drug delivery nanocarriers since they have been widely reviewed in recent publications (Devalapally et al., 2007; Peer et al., 2007; Dutta, 2007; Haley \& Frenkel, 2008; Lammers et al., 2008; Cho et al., 2008; Alexis et al., 2008). Therefore, in this chapter an overview will be restricted to liposomes, since these are probably the most used drug delivery system for small drug molecules.

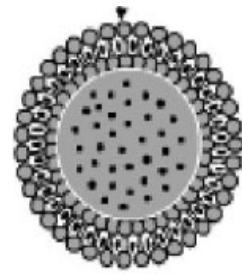

A

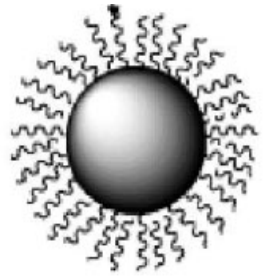

B

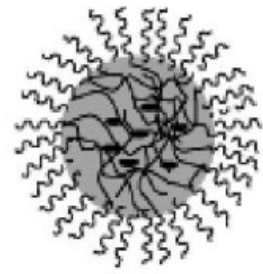

C

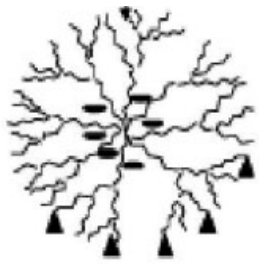

D

Fig. 3. Schematic representation of exemplificative nanocarriers for drug delivery. A Liposome; B Polymeric nanoparticle; C Micelle; D Dendrimer. Adapted from reference (Devalapally et al., 2007).

\subsection{Liposomes}

\subsubsection{General definition and main features}

Liposomes were firstly described by Bangham et al. (Bangham et al., 1965) and were originally called phospholipid spherules. Liposomes are self-assembling closed colloidal lipid vesicles (Fig. 4) with considerable potential for delivery of therapeutic agents due to several features: biodegradability, biocompatibility, simplicity, scaled-up production, low inherent toxicity, weak immunogenicity, versatility in structure and in physicochemical properties (lipid composition, size and surface charge) and ability to undergo surface engineering towards conjugation of polymers and targeting ligands (Immordino et al., 2006; Hofheinz et al., 2005; Cattel et al., 2003). Due to those specific attributes, liposomes have the 
ability to modulate in vivo behavior (pharmacokinetics and biodistribution profile) and/or solubility properties of drugs and to protect them from premature degradation or inactivation after intravenous administration (Fenske et al., 2008; Immordino et al., 2006; Drummond et al., 1999; Allen, 1998). In general, when a drug is encapsulated within a carrier, such as liposome (Fig. 4) the plasma clearance and volume of distribution decrease while the plasma circulation half-life $\left(\mathrm{t}_{1 / 2}\right)$ and area under the plasma concentration $v s$. time curve (AUC) increase (Gabizon et al., 2003).

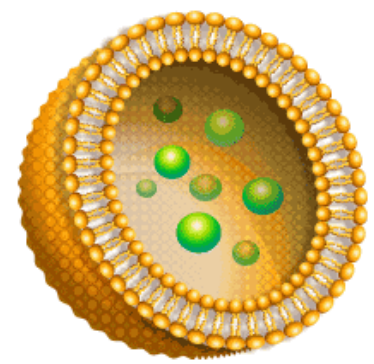

Fig. 4. Schematic representation of a liposome vehicle with drug molecules encapsulated in the aqueous internal compartment.

The pharmacokinetics, biodistribution and biological activity of a liposomal drug formulation are influenced by size, surface charge, lipid and drug doses, lipid composition, steric stabilization and route of administration (Charrois \& Allen, 2004, 2003; Nagayasu et al., 1999; Mayer et al., 1989).

The development of a successful therapeutic liposomal drug formulation must comply with three fundamental requisites: i) clear knowledge of the biology and physiology of the disease to be treated; ii) good understanding of the physicochemical properties of both the carrier and the drug and iii) determination of the pharmacokinetic and biodistribution changes induced in the drug by the liposomal vehicle (Allen, 1998).

Liposome structural types, physicochemical composition and preparation methods will not be overviewed in the present chapter since they have been thoroughly reviewed over the last two decades, in particular by Dr. Allen (Allen, 1998, 1997, 1994) and Dr. Lasic (Lasic et al., 1999) research groups.

\subsubsection{Medical applications}

In the past decades there have been major advances in the development of liposomal drug formulations suitable for several medical applications. In addition to their feature as drug delivery systems in the treatment of cancer, bacterial infections or ophthalmic disorders, current clinical applications of liposomes also include gene delivery, diagnostic imaging, vaccine adjuvant, photodynamic therapy, dermatology, hemoglobin or chelating agent transporter and enzyme replacement therapy (Fenske et al., 2008; Torchillin, 2007; Immordino et al., 2006; Torchillin, 2005; Gregoriadis \& Florence, 1993). The ultimate goal of an anticancer liposomal formulation is to improve overall therapeutic index of encapsulated drugs by increasing the antitumor activity and/or by reducing the toxicity profile, due to preferential delivery and accumulation at tumor tissue as compared to free drugs (Drummond et al., 1999; Gabizon, 1992). 


\subsubsection{In vivo behavior: From conventional to sterically stabilized liposomes}

Ideally, liposomal drug formulations should have a mean diameter centered on $100 \mathrm{~nm}$, a high drug-to-lipid ratio, an excellent retention of encapsulated drug(s) (while circulating in the blood) and a long circulation lifetime (from hours to days) (Fenske \& Cullis, 2005). In general, the short blood residence time and in vivo drug leakage profile of conventional liposomes hinder their clinical applicability. Liposomes are recognized and bounded by serum proteins (opsonins) (Fig. 4) and by complement system after which they are cleared from systemic circulation by reticulo-endothelial system (RES) cells of the liver, spleen and bone marrow (Immordino et al., 2006; Chonn et al., 1992; Papadjopolous et al., 1991). The physicochemical properties of liposomes, such as net surface charge, hydrophobicity, size, fluidity and packing of the lipid bilayer, influence their stability and the type of proteins that bind to them (Chonn et al., 1992). Moreover, lipid exchange with plasma lipoproteins can destabilize liposomes and lead to their rupture with release of entrapped content (Immordino et al., 2006). The use of saturated phospholipids with high phase transition temperature associated with cholesterol, but mostly surface coating with a synthetic hydrophilic polymer such as poly(ethylene glycol) - PEG (Fig. 4) or with ganglioside $\mathrm{G}_{\mathrm{M} 1}$, significantly extend bloodstream circulation time to several days and reduces RES clearance (Immordino et al., 2006; Gabizon et al., 2003; Allen, 1994, Papahadjopoulos et al., 1991; Gabizon \& Papahadjopoulos, 1988). Nevertheless, there are some disadvantages associated with PEG coating. There is some evidence that pegylated liposomes are not completely inert and can still induce activation of complement system (Immordino et al., 2006). Furthermore, the presence of PEG may hinder drug release to the target cell population (Harrington et al., 2002). Attempts have been made to solve these limitations by generating liposomes that are reversibly pegylated as described in detail elsewhere (Immordino et al., 2006; Harrington et al., 2002).

Pegylated liposomes are named sterically stabilized liposomes (SSL) or Stealth ${ }^{\circledR}$ due to a highly hydrated surface, constituted by the hydrophilic PEG and water molecules, that acts as a steric barrier and prevents protein adsorption and opsonization (Fig. 5) (Immordino et al., 2006; Andresen et al., 2005; Gabizon et al., 2003).

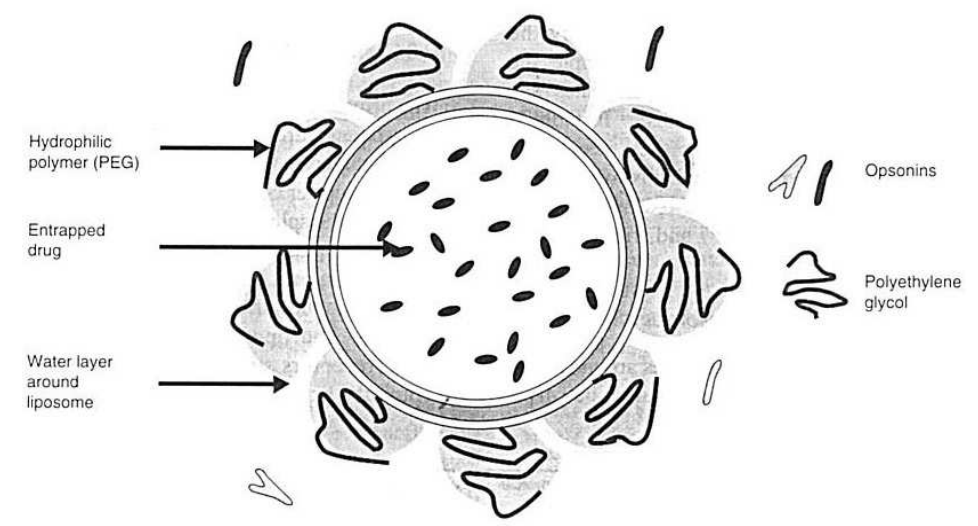

Fig. 5. Graphical representation of PEG-coated liposome (Stealth $\left.{ }^{\circledR}\right)$. Extent of opsonization of pegylated liposomes is significantly diminished due to their highly hydrated surface.

Adapted from reference (Allen, 1997). 


\subsubsection{The enhanced permeability and retention effect in tumor tissues}

Most solid tumors possess unique pathophysiological characteristics that are absent in normal tissues, such as extensive and unregulated angiogenesis, defective vascular architecture, enhanced vascular permeability, dysfunctional lymphatic drainage and increased production of a number of permeability mediators (Gabizon et al., 2006; Maeda et al., 2000). This enhanced permeability and retention effect (EPR) inherent to solid tumors (Fig. 6) (Maeda et al., 2000; Drummond et al., 1999) has been described in several experimental tumors and depends mainly on tumor volume, vascularization and leakage from blood vessels (Gabizon et al., 2006; Yuan et al., 1995). Long-circulating liposomal drug formulations with size diameter within the range of 100-150 nm demonstrate preferential extravasation through leaky tumor vasculature and passively accumulate in the interstitial space due to the EPR effect. The release of drug molecules from liposomes into the tumor interstitium provides locally drug delivery at therapeutic dose levels (Abraham et al., 2005; Drummond et al., 1999; Gabizon \& Papahadjopoulos, 1988). Interestingly, a particular study on tumor xenograft animal models reported that liposomes up to $400 \mathrm{~nm}$ can extravasate across tumor vessels and penetrate into tumor interstitium, suggesting that the threshold vesicle size of the pores is generally between 400 and $600 \mathrm{~nm}$ in diameter (Yuan et al., 1995). Nevertheless it is important to emphasize that the cut-off range mostly depends on tumor type. The extent of accumulation within the tumor is largely determined by the circulation lifetime of the liposomes (Song et al., 2006). Moreover, the impaired lymphatic drainage in the tumor interstitium favors the retention of liposomal formulations at the extravasation site, accentuating the passive targeting to solid tumors (Fig. 5) (Gabizon et al., 2006; Maeda et al., 2000; Drummond et al., 1999).

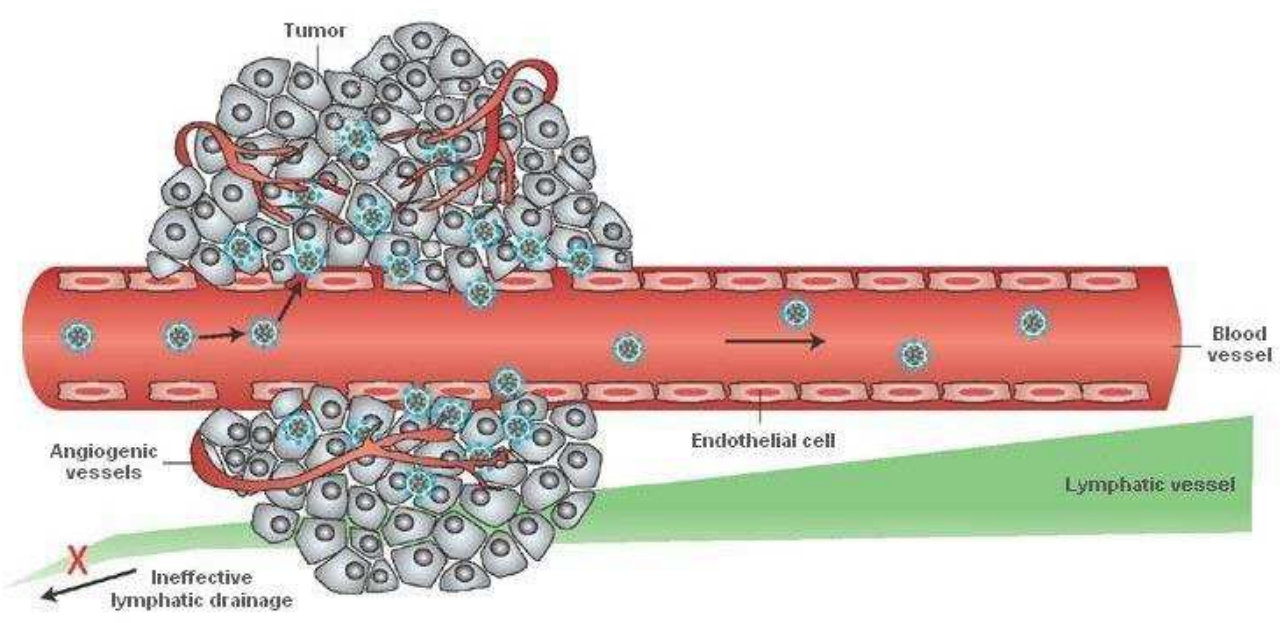

Fig. 6. Enhanced permeability and retention effect (EPR). Liposomes are shown as representative nanoparticles. Tumor targeting is achieved by passive extravasation of liposomes, from blood to tumor interstitium through highly permeable vasculature, and by accumulation in interstitial space due to non-functional lymphatic system in solid tumors. Adapted from reference (Peer et al., 2007). 


\subsubsection{Liposomal single drug formulations approved for clinical use or under clinical evaluation}

The success of liposomes as drug delivery systems has been reflected by the significant number of formulations which are FDA or EMA-approved for clinical use (Table 2) or undergoing clinical evaluation (Table 3).

Representative examples of liposomal single drug formulations that have gained regulatory approval for clinical use are Doxil ${ }^{\circledR}$ and Myocet ${ }^{\circledR}$. These LUV formulations encapsulating doxorubicin are being marketed for the treatment of several cancers, either as an individual formulation or in combination treatments (Table 2). Liposomal anthracyclines, namely doxorubicin, have raised significant interest due to their ability to decrease drug-related toxicity (cardiomyopathy, which can lead to congestive heart failure and death, bone marrow suppression, alopecia or nausea) with no associated loss of therapeutic activity (Abraham et al., 2005; Gabizon et al., 2003, 1998).

\begin{tabular}{|c|c|c|c|c|c|}
\hline $\begin{array}{l}\text { Formulation } \\
\text { brand name }\end{array}$ & Drug name & $\begin{array}{l}\text { Dosage form } \\
\text { / route }\end{array}$ & Therapeutic indication & Date & $\begin{array}{l}\text { Company } \\
\text { name }\end{array}$ \\
\hline Abelcet $^{(B)}$ & \multirow{3}{*}{ Amphotericin B } & $\begin{array}{l}\text { Lipid complex } \\
\text { /injection }\end{array}$ & Systemic fungal infection & 1995 & Enzon \\
\hline AmBisome $^{\circledR}$ & & $\begin{array}{l}\text { Liposomal/ } \\
\text { injection }\end{array}$ & Systemic fungal infection & 1997 & Astellas Pharma \\
\hline Amphotec $^{\circledR}$ & & $\begin{array}{l}\text { Lipid complex } \\
\text { /injection }\end{array}$ & Systemic fungal infection & 1996 & $\begin{array}{l}\text { Three Rivers } \\
\text { Pharms }\end{array}$ \\
\hline DaunoXome $^{\circledR}$ & $\begin{array}{l}\text { Daunorubicin } \\
\text { citrate }\end{array}$ & $\begin{array}{l}\text { Liposomal/ } \\
\text { injection }\end{array}$ & $\begin{array}{l}\text { AIDS-related Kaposi's } \\
\text { sarcoma } \\
\text { Breast cancer and other } \\
\text { solid tumors }\end{array}$ & 1996 & Diatos S.A. \\
\hline DepoCyt ${ }^{\circledR}$ & Cytarabine & $\begin{array}{l}\text { Liposomal/ } \\
\text { injection }\end{array}$ & $\begin{array}{l}\text { Lymphomatous meningitis } \\
\text { (intrathecal application) }\end{array}$ & 1999 & $\begin{array}{c}\text { Pacira } \\
\text { Pharmaceuticals } \\
\text { Inc. }\end{array}$ \\
\hline DepoDur $^{\circledR}$ & Morphine sulfate & $\begin{array}{l}\text { Liposomal/ } \\
\text { epidural }\end{array}$ & Post-surgical pain reliever & 2004 & $\begin{array}{c}\text { Pacira } \\
\text { Pharmaceuticals } \\
\text { Inc. }\end{array}$ \\
\hline $\operatorname{Doxil}^{\circledR}($ USA) & & & $\begin{array}{c}\text { AIDS-related Kaposi’s } \\
\text { sarcoma }\end{array}$ & 1995 & $\begin{array}{c}\text { Centocor Ortho } \\
\text { Biotech Inc. }\end{array}$ \\
\hline $\begin{array}{l}\text { Caelyx }{ }^{\circledR} \\
\text { (Europe) }\end{array}$ & Doxorubicin. $\mathrm{HCl}$ & $\begin{array}{l}\text { Liposomal/ } \\
\text { injection }\end{array}$ & $\begin{array}{l}\text { Advanced ovarian cancer } \\
\text { Metastatic breast cancer } \\
\text { Multiple myeloma } \\
\text { (combination with } \\
\text { bortezomib) }\end{array}$ & 1996 & $\begin{array}{l}\text { Schering Plough } \\
\text { Europe }\end{array}$ \\
\hline Myocet $^{\circledR}$ & Doxorubicin. $\mathrm{HCl}$ & $\begin{array}{l}\text { Liposomal/ } \\
\text { injection }\end{array}$ & $\begin{array}{l}\text { Metastatic breast cancer } \\
\text { (in combination with } \\
\text { cyclophosphamide) }\end{array}$ & 2000 & $\begin{array}{l}\text { Cephalon } \\
\text { Europe }\end{array}$ \\
\hline Visudyne $^{\circledR}$ & Verteporfin & $\begin{array}{l}\text { Liposomal/ } \\
\text { injection }\end{array}$ & $\begin{array}{c}\text { Age-related macular } \\
\text { degeneration }\end{array}$ & 2000 & $\begin{array}{l}\text { QLT Inc. } \\
\text { /Novartis }\end{array}$ \\
\hline
\end{tabular}

Table 2. Current FDA or EMA-approved liposomal single drug formulations for different clinical applications. Source: official website of USA Food and Drug Administration (FDA) http:/ / www.fda.gov (2010) and European Medicines Agency (EMA) http://www.ema.europa.eu (2010). 


\begin{tabular}{|c|c|c|c|c|}
\hline $\begin{array}{l}\text { Formulation } \\
\text { brand name }\end{array}$ & $\begin{array}{c}\text { Therapeutic } \\
\text { agent }\end{array}$ & Therapeutic indication & Company name & Status \\
\hline \multirow{2}{*}{\multicolumn{2}{|c|}{ Annamycin }} & $\begin{array}{l}\text { Acute lymphocytic leukemia } \\
\text { Acute myelogenous leukemia }\end{array}$ & $\begin{array}{c}\text { Callisto } \\
\text { Pharmaceuticals }\end{array}$ & Phase I/II \\
\hline & & Breast cancer & $\begin{array}{l}\text { New York University } \\
\text { School of Medicine }\end{array}$ & Phase I/II \\
\hline Aroplatin & $\begin{array}{c}\text { Platinum } \\
\text { agent NDDP }\end{array}$ & Colorectal cancer & $\begin{array}{c}\text { Aronex } \\
\text { Pharmaceuticals } \\
\end{array}$ & Phase II \\
\hline \multirow{3}{*}{ Atragen } & \multirow{3}{*}{ Tretinoin } & Hodgkin's lymphoma & $\begin{array}{l}\text { M.D. Anderson } \\
\text { Cancer Center }\end{array}$ & Phase II \\
\hline & & & Weill Medical & \\
\hline & & Metastatic kidney cancer & $\begin{array}{c}\text { College of Cornell } \\
\text { University }\end{array}$ & Phase II \\
\hline \multicolumn{2}{|c|}{ Cisplatin } & Lung cancer & Transave & Phase II \\
\hline LE-SN28 & $\begin{array}{l}\text { Irinotecan } \\
\text { metabolite } \\
\text { SN38 }\end{array}$ & Advanced cancer & NeoPharm & Phase I \\
\hline LEP-ETU & Paclitaxel & Advanced cancer & NeoPharm & Phase I \\
\hline Marqibo $^{\circledR}$ & Vincristine & $\begin{array}{l}\text { Acute lymphoblastic leukemia } \\
\text { Malignant melanoma }\end{array}$ & Hana Biosciences & $\begin{array}{l}\text { Phase II } \\
\text { Phase I/II }\end{array}$ \\
\hline \multicolumn{2}{|c|}{ Mitoxantrone } & Advanced cancer & NeoPharm & Phase I \\
\hline \multicolumn{2}{|c|}{ Nystatin } & $\begin{array}{c}\text { Systemic fungal infection } \\
\text { in patients with hematologic } \\
\text { cancer } \\
\end{array}$ & $\begin{array}{c}\text { Aronex } \\
\text { Pharmaceuticals }\end{array}$ & Phase III \\
\hline OSI-211 & Lurtotecan & $\begin{array}{c}\text { Ovarian cancer } \\
\text { Small cell lung carcinoma }\end{array}$ & OSI Pharmaceuticals & Phase II \\
\hline SPI-77 & Cisplatin & Ovarian cancer & $\begin{array}{l}\text { New York University } \\
\text { School of Medicine }\end{array}$ & Phase II \\
\hline Stimuvax $^{\circledR}$ & $\begin{array}{l}\text { BLP25 } \\
\text { vaccine }\end{array}$ & Non-small cell lung cancer & $\begin{array}{l}\text { EMD Serono and } \\
\text { Oncothyreon }\end{array}$ & Phase III \\
\hline \multicolumn{2}{|c|}{ Topotecan } & $\begin{array}{l}\text { Small cell lung cancer } \\
\text { Ovarian cancer } \\
\text { Other solid tumors }\end{array}$ & Hana Biosciences, Inc & Phase I \\
\hline \multicolumn{2}{|c|}{ Vinorelbine } & $\begin{array}{l}\text { Advanced solid tumors } \\
\text { Non-Hodgkin's lymphoma } \\
\text { Hodgkin's lymphoma }\end{array}$ & Hana Biosciences, Inc & Phase I \\
\hline
\end{tabular}

Table 3. Examples of emerging liposomal single drug formulations currently undergoing clinical evaluation for cancer treatment. Currently, some liposomal drugs have no brand name and, therefore, are identified by the drug name. Data was compiled from http:/ / www.phrma.org (2009) and from literature references (Lammers et al., 2008; Dutta, 2007; Torchillin, 2007, 2005; Immordino et al., 2006; Hofheinz et al., 2005) with actualization of current clinical status after consult of http://clinicaltrials.gov/ (2010).

Currently, there are no approved liposomal drugs for treatment of urologic cancers. Nevertheless, some liposomal drug formulations listed in Table 4 are under clinical evaluation for prostate cancer treatment. 


\begin{tabular}{|c|c|c|c|c|}
\hline Formulation name & Treatment & $\begin{array}{l}\text { Therapeutic } \\
\text { indication }\end{array}$ & Company name & Status \\
\hline \multirow{2}{*}{$\begin{array}{c}\text { Pegylated liposomal } \\
\text { doxorubicin } \\
\text { hydrochloride }\end{array}$} & Monotherapy & $\begin{array}{l}\text { Prostate cancer } \\
\text { (associated with } \\
\text { hyperthermia } \\
\text { treatment) }\end{array}$ & Celsion & Phase I \\
\hline & Monotherapy & \multirow{4}{*}{$\begin{array}{l}\text { Hormone- } \\
\text { refractory } \\
\text { prostate cancer } \\
(\text { HRPC })\end{array}$} & Ireland Cancer Center & Phase II \\
\hline Doxil $^{\circledR}$ & $\begin{array}{l}\text { In combination } \\
\text { with } \\
\text { estramustine }\end{array}$ & & Ortho Biotech, Inc. & Phase I/II \\
\hline Doxil $^{\circledR}$ & $\begin{array}{c}\text { In combination } \\
\text { with thalidomide }\end{array}$ & & Ortho Biotech, Inc. & Phase II \\
\hline Doxil $^{\circledR}$ & $\begin{array}{l}\text { In combination } \\
\text { with Taxotere }\end{array}$ & & $\begin{array}{c}\text { James Graham Brown } \\
\text { Cancer Center }\end{array}$ & Phase I/II \\
\hline
\end{tabular}

Table 4. Liposomal single drug formulations currently under clinical evaluation for prostate cancer treatment. Data was compiled after consult of http://clinicaltrials.gov/ (2010).

\subsubsection{Liposomal formulations of anticancer drug combinations}

\subsubsection{General considerations}

The use of drug combinations has been standard of care for the treatment of cancer over the last decades. Nevertheless, the application of liposomes as carriers for anticancer drug combinations has been described in literature only in the last few years (Tardi et al., 2009; Harasym et al., 2007; Tardi et al., 2007; Mayer et al, 2006). To our knowledge, there are no liposomal drug combinations approved for clinical application. As previously mentioned in section 3.1 drug combinations can act synergistically, additively or antagonistically depending on the ratio of the agents being combined (Chou, 2006). While this relationship can be readily evaluated in vitro, where drug ratios can be controlled, the translation of those ratios to the clinical setting is complex due to the independent pharmacokinetics, biodistribution and/or metabolism of the individual drugs intravenously administered as aqueous-based free drug cocktail (Mayer et al., 2006; Lee, 2006). Therefore, the referred uncoordinated pharmacokinetics results in exposure of tumor cells to drug concentrations below therapeutic threshold level or to antagonistic drug ratios with concomitant loss of therapeutic activity (Mayer \& Janoff, 2007; Harasym et al, 2007). The inability to control drug ratios in systemic circulation, and mainly in tumor tissue, may partly explain the short outcome in clinical efficacy seen for conventional free drug combinations (Mayer \& Janoff, 2007).

Drug delivery systems, such as liposomes, can control the release of drug combinations such that fixed drug ratios are maintained after systemic administration. This tight control provides significant improvements in efficacy as compared to free drug cocktail and to individual liposomal drugs (Tardi et al., 2009, Mayer \& Janoff, 2007; Harasym et al., 2007; Mayer et al., 2006; Lee, 2006). In 2006, Mayer and colleagues were the first to investigate the importance of maintaining an optimal drug combination ratio in vivo through drug encapsulation in liposomes (Mayer et al., 2006). Further studies (Tardi et al., 2009; Harasym et al., 2007) have demonstrated that in vitro drug interaction effects can be translated in vivo since liposomes can synchronize pharmacokinetics and biodistribution of drug combinations and deliver them to tumor tissue at a specific drug ratio (Fig.7, lower panel). 
This "ratiometric" dosing approach has the potential to be applied to other diseases besides cancer in which multiple interacting mechanisms are responsible for disease progression or response to therapeutic interventions (Mayer \& Janoff, 2007). In contrast, the combination injected as a free drug cocktail rapidly distributes into healthy and tumor tissues at drug ratios that differ from the administered one (Fig.7, upper panel).
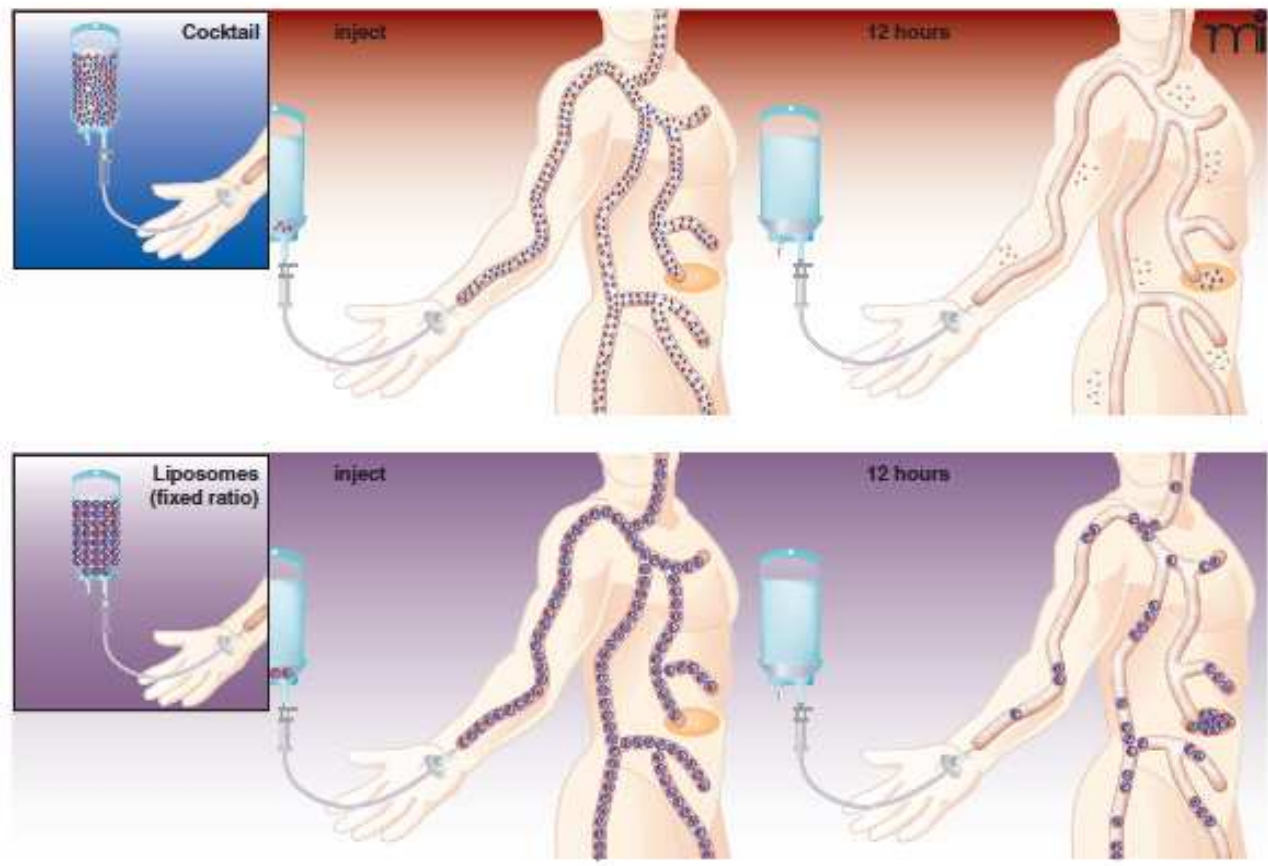

Fig. 7. Description of how clinical application of drug-drug synergy depends on controlled delivery of the desired drug ratio to the in vivo target. Upper panel - a drug cocktail is prepared at the desired ratio but biodistribution, metabolism and excretion processes will act differentially on the two drugs and cause the ratio to vary after intravenous injection. The two drugs distribute extensively into tissues shortly after injection and the ratio that reaches the tumor has been displaced 5-fold from the initially injected 1:1 ratio. Lower panel - liposomes that contain the synergistic 1:1 ratio maintain and selectively deliver this drug ratio to the tumor. The appropriately designed drug delivery vehicle maintains the drugs in the blood at higher concentrations for extended periods of time and, most importantly, at the effective synergistic ratio. Reproduced from reference (Mayer \& Janoff, 2007).

Therefore, it can be concluded that liposome nanotechnology constitutes a valuable tool for preclinical assessment of drug combinations for clinical development (Lee, 2006). Advantages of liposomal drug combination delivery are summarized in Table 5.

Celator Pharmaceuticals were pioneers in liposomal drug combination design and have some products under clinical development and preclinical programs, which are summarized in Table 6. Currently, CPX-351 and CPX-1 are the only liposomal drug combinations under testing in clinical trials (http://clinicaltrials.gov (2010)) but none of them is intended for prostate cancer therapy. 
1. Injection of multiple drugs simultaneously

2. Identical pharmacokinetic profile for multiple drugs reflecting the profile of the lipid carrier

3. Tight control of drug concentration at the target sites by changing the drug combined ratio in the liposome

4. Maximal combination effects can be achieved by synergistic action of multiple drugs after cellular uptake

5. Versatile design of the loading methods and membrane lipid composition to control drug release

6. Improvement of patient compliance and quality of life due to reduced number of injections and of side effects while increasing efficacy

Table 5. Advantages of liposomal drug combination delivery. Adapted from reference (Bae et al., 2007)

\begin{tabular}{cccc}
\hline Product name & Liposomal drug combination & Therapeutic indication & Status \\
\hline CPX-351 & Cytarabine : daunorubicin & Acute myeloid leukemia & Phase II \\
CPX-1 & Irinotecan HCI : floxuridine & Colorectal neoplasms & Phase II \\
CPX-571 & Irinotecan $\mathrm{HCl}:$ cisplatin & Small cell lung cancer & Preclinical \\
CPX-8XY & Unknown & Unknown & Research \\
\hline
\end{tabular}

Table 6. Liposomal drug combinations developed by Celator Pharmaceuticals. Source: Celator Pharmaceuticals (http:/ / www.celatorpharma.com (2010)).

\subsubsection{Design of liposomal formulations for drug combination delivery}

The concept of combining drugs, with dissimilar physicochemical properties, into a single vehicle, that efficiently encapsulates both drugs and releases them at the same rate after administration in vivo, represents a major scientific and technical challenge. Presently, liposomal encapsulation represents a new paradigm for formulating anticancer drug combinations. Although this approach has emerged as a promising strategy for cancer treatment, there are a limited number of research studies reporting successful drug coloading in the same carrier (Tardi et al., 2009; Zhao et al., 2008; Harasym et al., 2007; Mayer et al., 2006). This is likely the result of technical difficulties associated with the efficient and stable encapsulation of two drugs inside a single carrier as well as challenges in controlling the drug leakage rate and still maintaining the entrapped drug:drug ratio after systemic administration (Harasym et al., 2007; Tardi et al., 2007).

There are three different approaches to formulate a drug combination involving liposomal design: i) combination of a liposomal drug with a free drug; ii) encapsulation of two drugs in individual liposomal carriers that are subsequently combined at the desired ratio and iii) co-encapsulation of two drugs in the same carrier by means of a simultaneous or a sequential drug loading. The advantages and limitations of each strategy are discussed below in more detail and in the mentioned order:

i. A liposomal drug formulation can be administered together with a free drug but unfavorable liposome-free drug interactions may occur, such as hydrophobic interactions or loading of the free drug into liposomes exhibiting a $\mathrm{pH}$ gradient 
(Waterhouse et al., 2001; Mayer et al., 1999). Therefore, these interactions may induce changes in the pharmacokinetic parameters of the free and encapsulated drugs as well as of the lipid carrier, leading to decreased efficacy and/or increased toxicity (Waterhouse et al., 2001).

ii. Perhaps the most straightforward approach to coordinate the pharmacokinetics of a drug combination would be to encapsulate each drug independently into different liposomes that provide the required drug retention properties and, subsequently, to mix the liposomes in a single suspension at the desired drug:drug ratio. Nevertheless, this protocol of formulating drugs in individual liposomes and ultimately administrate to patients would be extremely expensive due to the high costs inherent to lipid constituents and to the manufacturing process of two separate formulations (Harasym et al., 2007).

iii. Co-encapsulation of two drugs in the same liposomal carrier seems to be a preferable solution as compared to administration of individual liposomal drugs since it reduces cost production, minimizes lipid load to the patient, which has been associated to infusion-related side effects, and eliminates the potential interference that each liposome population may exert in the pharmacokinetic profile of the other (Harasym et al., 2007; Tardi et al., 2007). Furthermore, co-encapsulation overcomes potential uncertainties about drug biodistribution provided by the different liposome compositions. By encapsulating a drug combination into a single liposome, the two agents are no longer metabolized and eliminated independently but rather distributed as a unit, dictated by the characteristics of the carrier. However, this approach represents a technical challenge in order to develop a liposomal formulation that matches drug release kinetics for both drugs. To accomplish such purpose, experimental parameters and liposome features, such as drug loading methods and lipid composition, must be systematically optimized during formulation development (Harasym et al., 2007).

\subsubsection{Development of a liposomal drug combination for prostate cancer: an example}

In the last few years our group has performed an extensive and systematic preclinical study to evaluate the in vitro biologic activity of traditional and novel anticancer drugs and, ultimately, identify new drug combinations with therapeutic potential for the treatment of prostate cancer. Combinations were selected among different drugs (ciprofloxacin, docetaxel, doxorubicin, etoposide, imatinib, mitoxantrone and vinblastine) representative of distinct mechanisms of action. Several treatment schemes were evaluated by varying schedule, type of administration (simultaneous or sequential) and drug:drug molar ratio. The nature of antiproliferative combined effects (synergism, additivity or antagonism) against metastatic prostate cancer cell lines was quantitatively assessed by the median effect analysis method, whose main parameters are combination index (CI) and dose reduction index (DRI) (Pinto et al. 2011a, 2009).

Combination of two drugs tested simultaneously, comprising at least one topoisomerase II inhibitor, result in mild antagonistic effects against PC-3 and LNCaP cells. This antagonism of growth inhibition effects is translated by a CI superior to 1 and by a DRI inferior to twofold. In contrast, imatinib-mitoxantrone and ciprofloxacin-etoposide simultaneous combinations interact additively in inhibiting PC-3 cell growth, yielding CI values close to 1 and DRI values of 2.6 and 3.5-fold for mitoxantrone and etoposide, respectively (Pinto et al. 2011a, 2009). 
The use of liposomes as drug delivery systems has been exploited in order to improve overall therapeutic index of anticancer drugs by increasing their antitumor activity and/or by reducing their toxicity profile. The main goal of our studies was to develop and characterize a novel liposomal formulation, for simultaneous co-loading and delivery of a drug combination previously identified in cytotoxicity screening studies performed in our laboratory, and to evaluate its in vitro and in vivo antitumor activity against HRPC preclinical models. The rationale for selecting imatinib-mitoxantrone combination was to investigate if co-loading of those two drugs into a liposome could translate the additive growth inhibition effects exerted on PC-3 cells when these drugs were combined simultaneously in the free form. Another selection criterion was that these drugs exhibit non-overlapping toxicity profiles and different mechanisms of action, so potential side effects and resistance phenomena could be minimized. Moreover, this combination is innovative for prostate cancer therapy since it conciliates a conventional antineoplastic drug (mitoxantrone), which is standard of care for palliative treatment of HRPC, with a molecular-targeted agent (imatinib), which has exhibited antitumor activity against in vitro and in vivo HRPC models.

Systematic development studies, by varying drug loading methods and incubation conditions, were carried out in order to design a liposomal imatinib-mitoxantrone (LIM) formulation that while being stable would exhibit adequate features for intravenous administration. Obtained results provide clear evidence that the two drugs can be simultaneously loaded, with high encapsulation efficiency $(>95 \%)$, in a single liposomal carrier using a transmembrane $(\mathrm{NH} 4)_{2} \mathrm{SO}_{4}$ gradient-based procedure. According to literature, our study was the first to report an active loading method for imatinib (Pinto et al. 2011b).

In vitro studies performed on PC-3 cells showed that LIM formulation, at an optimized drug:drug molar ratio, exhibits enhanced tumor cell growth inhibition and promotes a 2.6fold reduction of $\mathrm{IC}_{50}$ as compared to single liposomal mitoxantrone. This dose reduction is equivalent to the one found for mitoxantrone in free drug combination against the same cell line (Pinto et al. 2011a). Therefore, the therapeutic gain in mitoxantrone efficacy, mediated by imatinib and that result from free drug combination, is also attainable after liposomal encapsulation of the drugs at an optimized drug:drug ratio (Pinto et al. 2011b).

In vivo therapeutic activity of developed liposomal formulations, comprising different doses of single or imatinib-combined mitoxantrone, was evaluated in a nude mice bearing subcutaneous PC-3 xenograft model. Obtained results clearly demonstrate that intravenous administration of the liposomal formulation co-loading a low mitoxantrone dose $(0.5$ $\mathrm{mg} / \mathrm{kg})$ with imatinib $(10 \mathrm{mg} / \mathrm{kg})$ enables a tumor growth inhibition similar to the one yielded by single liposomal mitoxantrone $(2.0 \mathrm{mg} / \mathrm{kg})$, i.e. with a 4 -fold inferior dose. This dose reduction could minimize the occurrence of side effects and hence increase therapeutic index of mitoxantrone (Pinto et al. 2011b).

Our results clearly emphasize the potential of incorporating clinically relevant drug combinations, at specific therapeutic ratios, within a lipid-based delivery system. Our research study is the first to provide a proof-of-principle for imatinib use in improving in vitro and in vivo antitumor efficacy of liposomal mitoxantrone. Overall, the developed LIM formulation constitutes a novel nanotechnology-based drug combined platform with improved therapeutic outcome against HRPC. 


\section{Conclusion}

The up-to-date approach intended to develop novel chemotherapeutic drug combinations should be based on a rational selection of the drugs to be combined and on a systematic and quantitative screening of the ratio-dependent antiproliferative effects against human tumor cell lines. Drug combination studies on tumor cell lines, using a quantitative method to evaluate the nature of drug interactions, allow a more rational design of future chemotherapy protocols.

The translation of specific drug ratios, previously selected in vitro, to the clinical setting is complex due to the independent pharmacokinetics and biodistribution of individual drugs intravenously administered as aqueous-based free drug cocktail. The referred uncoordinated pharmacokinetics results in exposure of tumor cells to drug concentrations below therapeutic threshold level or to antagonistic drug ratios with concomitant loss of therapeutic activity. The inability to control drug ratios in systemic circulation, and mainly in tumor tissue, may partly explain the short outcome in clinical efficacy seen for conventional free drug combinations.

The extensive in vitro information on drug ratios can be used to formulate drug combinations in drug delivery systems. The use of liposomes as drug delivery systems has been successfully exploited in order to improve overall therapeutic index of anticancer drugs by increasing their antitumor activity and/or by reducing their toxicity profile. Successful clinical application of this rationally-designed approach to cancer therapy depends on the development of a liposomal formulation, with specific features, that delivers the drug combination in vivo so that the effective drug ratio is maintained after systemic administration and is ultimately exposed to tumors.

\section{References}

Abraham S.A., Waterhouse D.N., Mayer L.D., Cullis P.R., Madden T.D. \& Bally M.B. (2005). The liposomal formulation of doxorubicin. Methods Enzymol, vol.391, (February 2005), pp. 71-97, ISNN 0076-6879

Alexis F., Rhee J.W., Richie J.P., Radovic-Moreno A.F., Langer R. \& Farokhzad O.C. (2008). New frontiers in nanotechnology for cancer treatment. Urol Oncol, vol.26, No.1, (January 2008), pp. 74-85, ISNN 1078-1439

Allen T.M. (1998). Liposomal drug formulations. Rationale for development and what we can expect for the future. Drugs, vol.56, No.5, (November 1998), pp. 747-756, ISNN 0012-6667

Allen T.M. (1997). Liposomes. Opportunities in drug delivery. Drugs, vol.54, No.4, (January 1997), pp. 8-14, ISNN 0012-6667

Allen T.M. (1994). Long-circulating (sterically stabilized) liposomes for targeted drug delivery. Trends Pharmacol Sc, vol.15, No.7, (July 1994), pp. 215-220, ISNN 0165-6147

Andresen T.L., Jensen S.S. \& Jorgensen K. (2005). Advanced strategies in liposomal cancer therapy: problems and prospects of active and tumor specific drug release. Prog Lipid Res, vol.44, No.1, (March 2005), pp. 68-97, ISNN 0163-7827

Armstrong A.J. \& Carducci M.A. (2006). New drugs in prostate cancer. Curr Opin Urol, vol.16, No.3, (May 2006), pp. 138-145, ISNN 0963-0643

Bae Y., Diezi T.A., Zhao A. \& Kwon G.S. (2007). Mixed polymeric micelles for combination cancer chemotherapy through the concurrent delivery of multiple chemotherapeutic agents. J Control Release, vol.122, No.3, (August 2007), pp. 324-330, ISNN 1873-4995 
Bangham A.D., Standish M.M. \& Watkins J.C. (1965). Diffusion of univalent ions across the lamellae of swollen phospholipids. J Mol Biol, vol.13, No.1, (August 1965), pp. 238252, ISNN 0022-2836

Budman D.R., Calabro A. \& Kreis W. (2002). Synergistic and antagonistic combinations of drugs in human prostate cancer cell lines in vitro. Anticancer Drugs, vol.13, No.10, (November 2002), pp. 1011-1016, ISNN 0959-4973

Cattel L., Ceruti M. \& Dosio F. (2003). From conventional to stealth liposomes: a new frontier in cancer chemotherapy. Tumori, vol.89, No.3, (August 2003), pp. 237-249, ISNN 0300-8916

Charrois G.J. \& Allen T.M. (2004). Drug release rate influences the pharmacokinetics, biodistribution, therapeutic activity, and toxicity of pegylated liposomal doxorubicin formulations in murine breast cancer. Biochim Biophys Acta, vol.1663, No.1-2, (January 2004), pp. 167-177, ISNN 0006-3002

Charrois G.J. \& Allen T.M. (2003). Rate of biodistribution of STEALTH liposomes to tumor and skin: influence of liposome diameter and implications for toxicity and therapeutic activity. Biochim Biophys Acta, vol.1609, No.1, (January 2003), pp. 102108, ISNN 0006-3002

Cho K., Wang X., Nie S., Chen Z.G. \& Shin D.M. (2008). Therapeutic nanoparticles for drug delivery in cancer. Clin Cancer Res, vol.14, No.5, (March 2008), pp. 1310-1316, ISNN 1078-0432

Chonn A., Semple S.C. \& Cullis P.R. (1992). Association of blood proteins with large unilamellar liposomes in vivo. Relation to circulation lifetimes. J Biol Chem, vol.267, No.26, (September 1992), pp. 18759-18765, ISNN 0021-9258

Chou T.C. \& Talalay P. (1984). Quantitative analysis of dose-effect relationships: the combined effects of multiple drugs or enzyme inhibitors. Adv Enzyme Regul, vol.22, (January 1984), pp. 27-55, ISNN 0065-2571

Chou T.C., Motzer R.J., Tong Y. \& Bosl G.J. (1994). Computerized quantitation of synergism and antagonism of taxol, topotecan, and cisplatin against human teratocarcinoma cell growth: a rational approach to clinical protocol design. J Natl Cancer Inst, vol.86, No.20, (October 1994), pp. 1517-1524, ISNN 0027-8874

Chou T.C. (2010). Drug combination studies and their synergy quantification using the Chou-Talalay method. Cancer Res, vol. 70, No.2, (January 2010), pp. 440-446, ISNN 1538-7445

Chou T.C. (2006). Theoretical basis, experimental design, and computerized simulation of synergism and antagonism in drug combination studies. Pharmacol Rev, vol.58, No.3, (September 2006), pp. 621-681, ISNN 0031-6997

Chou T.C. (1998). Drug combinations: from laboratory to practice. J Lab Clin Med 132, No.1, (July 1998), pp. 6-8, ISNN 0022-2143

Chou T.C. (1994). Assessment of synergistic and antagonistic effects of chemotherapeutic agents in vitro. Contrib Gynecol Obstet, vol.19, (January 1994), pp. 91-107, ISNN 0304-4246

Chou T.C. (1976). Derivation and properties of Michaelis-Menten type and Hill type equations for reference ligands. J Theor Biol, vol.59, No.2, (july 1976), pp. 253-276, ISNN 0022-5193

De La Taille A., Vacherot F., Salomon L., Druel C., Gil Diez De Medina S., Abbou C., Buttyan R. \& Chopin D. (2001). Hormone-refractory prostate cancer: a multi-step and multi-event process. Prostate Cancer Prostatic Dis, vol.4, No.4, (December 2001), pp. 204-212, ISNN 1476-5608 
Devalapally H., Chakilam A. \& Amiji M.M. (2007). Role of nanotechnology in pharmaceutical product development. J Pharm Sci, vol.96, No.10, (August 2007), pp. 2547-2565, ISNN 0022-3549

Dong J.T. (2006). Prevalent mutations in prostate cancer. J Cell Biochem 97, No.3, (November 2005), pp. 433-447, ISNN 0730-2312

Drummond D.C., Meyer O., Hong K., Kirpotin D.B. \& Papahadjopoulos D. (1999). Optimizing liposomes for delivery of chemotherapeutic agents to solid tumors. Pharmacol Rev, vol.51, No.4, (December 1999), pp. 691-743, ISNN 0031-6997

Dutta R.C. (2007). Drug carriers in pharmaceutical design: promises and progress. Curr Pharm Des, vol.13, No.7, (March 2007), pp. 761-769, ISNN 1873-4286

Fenske D.B., Chonn A. \& Cullis P.R. (2008). Liposomal nanomedicines: an emerging field. Toxicol Pathol, vol.36, No.1, (March 2008), pp. 21-29, ISNN 1533-1601

Fenske D.B. \& Cullis P.R. (2005). Entrapment of small molecules and nucleic acid-based drugs in liposomes. Methods Enzymol, vol.391, (February 2005), pp. 7-40, ISNN 0076-6879

Gabizon A.A., Shmeeda H. \& Zalipsky S. (2006). Pros and cons of the liposome platform in cancer drug targeting. J Liposome Res, vol.16, No.3, (September 2006), pp. 175-183, ISNN 0898-2104

Gabizon A.A. (1992). Selective tumor localization and improved therapeutic index of anthracyclines encapsulated in long-circulating liposomes. Cancer Res, vol.52, No.4, (February 1992), pp. 891-896, ISNN 0008-5472

Gabizon A., Shmeeda H. \& Barenholz Y. (2003). Pharmacokinetics of pegylated liposomal Doxorubicin: review of animal and human studies. Clin Pharmacokinet, vol.42, No.5, (may 2003), pp. 419-436, ISNN 0312-5963

Gabizon A. \& Papahadjopoulos D. (1988). Liposome formulations with prolonged circulation time in blood and enhanced uptake by tumors. Proc Natl Acad Sci USA, vol.85, No.18, (September 1988), pp. 6949-6953, ISNN 0027-8424

Gabizon A., Goren D., Cohen R. \& Barenholz Y. (1998). Development of liposomal anthracyclines: from basics to clinical applications. J Control Release, vol.53, No.1-3, (September 1998), pp. 275-279, ISNN 0168-3659

Goldie J.H. (2001). Drug resistance in cancer: a perspective. Cancer Metastasis Rev, vol.20, No.1-2, (February 2002), pp. 63-68, ISNN 0167-7659

Gregoriadis G. \& Florence A.T. (1993). Liposomes in drug delivery. Clinical, diagnostic and ophthalmic potential. Drugs, vol.45, No.1, (January 1993), pp. 15-28, ISNN 00126667

Haley B. \& Frenkel E. (2008). Nanoparticles for drug delivery in cancer treatment. Urol Oncol, vol.26, No.1, (January 2008), pp. 57-64, ISNN 1078-1439

Hanahan D. \& Weinberg R.A. (2000). The hallmarks of cancer. Cell, vol.100, No.1, (January 2000), pp. 57-70, ISNN 0092-8674

Harasym T.O., Tardi P.G., Harasym N.L., Harvie P., Johnstone S.A. \& Mayer L.D. (2007). Increased preclinical efficacy of irinotecan and floxuridine coencapsulated inside liposomes is associated with tumor delivery of synergistic drug ratios. Oncol Res, vol.16, No.8, (October 2007), pp. 361-374, ISNN 0965-0407

Harrington K.J., Syrigos K.N. \& Vile R.G. (2002). Liposomally targeted cytotoxic drugs for the treatment of cancer. J Pharm Pharmacol, vol.54, No.12, (January 2003), pp. 15731600, ISNN 0022-3573

Hofheinz R.D., Gnad-Vogt S.U., Beyer U. \& Hochhaus A. (2005). Liposomal encapsulated anti-cancer drugs. Anticancer Drugs, vol.16, No.7, (July 2005), pp. 691-707, ISNN 0959-4973 
Immordino M.L., Dosio F. \& Cattel L. (2006). Stealth liposomes: review of the basic science, rationale, and clinical applications, existing and potential. Int J Nanomedicine, vol.1, No.3, (August 2007), pp. 297-315, ISNN 1176-9114

Ismael G.F., Rosa D.D., Mano M.S. \& Awada A. (2008). Novel cytotoxic drugs: old challenges, new solutions. Cancer Treat Rev, vol.34, No.1, (October 2007), pp. 81-91, ISNN 0305-7372

Kreis W., Budman D.R. \& Calabro A. (2001). A reexamination of PSC 833 (Valspodar) as a cytotoxic agent and in combination with anticancer agents. Cancer Chemother Pharmacol, vol.47, No.1, (February 2001), pp. 78-82, ISNN 0344-5704

Lammers T., Hennink W.E. \& Storm G. (2008). Tumour-targeted nanomedicines: principles and practice. Br J Cancer, vol.99, No.3, (July 2008), pp. 392-397, ISNN 1532-1827

Lasic D.D., Vallner J.J. \& Working P.K. (1999). Sterically stabilized liposomes in cancer therapy and gene delivery. Curr Opin Mol Ther, vol.1, No.2, (November 2001), pp. 177-185, ISNN 1464-8431

Lee R.J. (2006). Liposomal delivery as a mechanism to enhance synergism between anticancer drugs. Mol Cancer Ther, vol.5, No.7, (August 2006), pp. 1639-1640, ISNN $1535-7163$

Maeda H., Wu J., Sawa T., Matsumura Y. \& Hori K. (2000). Tumor vascular permeability and the EPR effect in macromolecular therapeutics: a review. J Control Release, vol.65, No.1-2, (March 2000), pp. 271-284, ISNN 0168-3659

Mayer L.D., Harasym T.O., Tardi P.G., Harasym N.L., Shew C.R., Johnstone S.A., Ramsay E.C., Bally M.B. \& Janoff A.S. (2006). Ratiometric dosing of anticancer drug combinations: controlling drug ratios after systemic administration regulates therapeutic activity in tumor-bearing mice. Mol Cancer Ther, vol.5, No.7, (Augusr 2006), pp. 1854-1863, ISNN 1535-7163

Mayer L.D. \& Janoff A.S. (2007). Optimizing combination chemotherapy by controlling drug ratios. Mol Interv, vol.7, No.4, (Sptember 2007), pp. 216-223, ISNN 1534-0384

Mayer L.D., Reamer J. \& Bally M.B. (1999). Intravenous pretreatment with empty pH gradient liposomes alters the pharmacokinetics and toxicity of doxorubicin through in vivo active drug encapsulation. J Pharm Sci, vol.88, No.8, (January 1999), pp. 96102, ISNN 0022-3549

Mayer L.D., Tai L.C., Ko D.S., Masin D., Ginsberg R.S., Cullis P.R. \& Bally M.B. (1989). Influence of vesicle size, lipid composition, and drug-to-lipid ratio on the biological activity of liposomal doxorubicin in mice. Cancer Res, vol.49, No.21, (November 1989), pp. 5922-5930, ISNN 0008-5472

Merlin J.L. (1994). Concepts of synergism and antagonism. Anticancer Res, vol.14, No.6A, (November 1994), pp. 2315-2319, ISNN 0250-7005

Mitchell S., Abel P., Ware M., Stamp G. \& Lalani E. (2000). Phenotypic and genotypic characterization of commonly used human prostatic cell lines. BJU Int, vol.85, No.7, (May 2000), pp. 932-944, ISNN 1464-4096

Nagayasu A., Uchiyama K. \& Kiwada H. (1999). The size of liposomes: a factor which affects their targeting efficiency to tumors and therapeutic activity of liposomal antitumor drugs. Adv Drug Deliv Rev, vol.40, No.1-2, (June 1999), pp.75-87, ISNN 1872-8294

Papahadjopoulos D., Allen T.M., Gabizon A., Mayhew E., Matthay K., Huang S.K., Lee K.D., Woodle M.C., Lasic D.D. \& Redemann C. (1991). Sterically stabilized liposomes: improvements in pharmacokinetics and antitumor therapeutic efficacy. Proc Natl Acad Sci USA, vol.88, No.24, (December 1991), pp. 11460-11464, ISNN 0027-8424 
Peer D., Karp J.M., Hong S., Farokhzad O.C., Margalit R. \& Langer R. (2007). Nanocarriers as an emerging platform for cancer therapy. Nat Nanotechnol, vol.2, No.12, (July 2008), pp. 751-760, ISNN 1748-3395

Pinto A., Moreira J., Simões S. (2009). Ciprofloxacin sensitizes hormone-refractory prostate cancer cell lines to doxorubicin and docetaxel treatment on a schedule-dependent manner. Cancer Chemother Pharmacol, vol.64, No.3, (December 2008), pp. 445-454, ISNN 1432-0843

Pinto A., Ângelo S., Moreira J., Simões S. (2011a). Schedule treatment design and quantitative in vitro evaluation of chemotherapeutic combinations for metastatic prostate cancer therapy. Cancer Chemother Pharmacol, vol.67, No.2, (October 2010), pp. 275-284, ISNN 1432-0843

Pinto A., Moreira J., Simões S. (2011b). Liposomal imatinib-mitoxantrone combination: formulation development and therapeutic evaluation in an animal model of prostate cancer. Prostate, vol.71, No.1, (July 2010), pp.81-90, ISNN 1097-0045

Ramsay E.C., Dos Santos N., Dragowska W.H., Laskin J.J. \& Bally M.B. (2005). The formulation of lipid-based nanotechnologies for the delivery of fixed dose anticancer drug combinations. Curr Drug Deliv, vol.2, No.4, (nvember 2005), pp. 341-351, ISNN 1567-2018

Song H., Zhang J., Han Z., Zhang X., Li Z., Zhang L., Fu M., Lin C. \& Ma J. (2006). Pharmacokinetic and cytotoxic studies of pegylated liposomal daunorubicin. Cancer Chemother Pharmacol, vol.57, No.5, (September 2005), pp.591-598, ISNN 0344-5704

Suggitt M. \& Bibby M.C. (2005). 50 years of preclinical anticancer drug screening: empirical to target-driven approaches. Clin Cancer Res, vol.11, No.3, (February 2005), pp.971981, ISNN 078-0432

Tardi P., Johnstone S., Harasym N., Xie S., Harasym T., Zisman N., Harvie P., Bermudes D. \& Mayer L. (2009). In vivo maintenance of synergistic cytarabine:daunorubicin ratios greatly enhances therapeutic efficacy. Leuk Res, vol.33, No.1, (August 2008), pp.129-139, ISNN 0145-2126

Tardi P.G., Gallagher R.C., Johnstone S., Harasym N., Webb M., Bally M.B. \& Mayer L.D. (2007). Coencapsulation of irinotecan and floxuridine into low cholesterolcontaining liposomes that coordinate drug release in vivo. Biochim Biophys Acta, vol.1768, No.3, (January 2007), pp.678-687, ISNN 0006-3002

Torchilin V.P. (2007). Targeted pharmaceutical nanocarriers for cancer therapy and imaging. Aaps J, vol.9, No.2, (July 2007), pp. E128-147, ISNN 1550-7416

Torchilin V.P. (2005). Recent advances with liposomes as pharmaceutical carriers. Nat Rev Drug Discov, vol.4, No.2, (February 2005), pp. 145-160, ISNN 1474-1776

Waterhouse D.N., Dos Santos N., Mayer L.D. \& Bally M.B. (2001). Drug-drug interactions arising from the use of liposomal vincristine in combination with other anticancer drugs. Pharm Res, vol.18, No.9, (October 2001), pp.1331-1335, ISNN 0724-8741

Yuan F., Dellian M., Fukumura D., Leunig M., Berk D.A., Torchilin V.P. \& Jain R.K. (1995). Vascular permeability in a human tumor xenograft: molecular size dependence and cutoff size. Cancer Res, vol.55, No.17, (September 1995), pp. 3752-3756, ISNN 0008-5472

Zhao X., Wu J., Muthusamy N., Byrd J.C. \& Lee R.J. (2008). Liposomal coencapsulated fludarabine and mitoxantrone for lymphoproliferative disorder treatment. J Pharm Sci, vol.97, No.4, (August 2007), pp.1508-1518, ISNN 0022-3549

Zoli W., Ricotti L., Tesei A., Barzanti F. \& Amadori D. (2001). In vitro preclinical models for a rational design of chemotherapy combinations in human tumors. Crit Rev Oncol Hematol, vol.37, No.1, (February 2001), pp.69-82, ISNN 1040-8428 


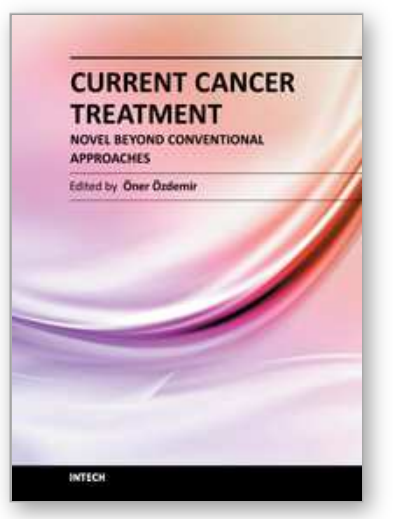

\author{
Current Cancer Treatment - Novel Beyond Conventional \\ Approaches \\ Edited by Prof. Oner Ozdemir
}

ISBN 978-953-307-397-2

Hard cover, 810 pages

Publisher InTech

Published online 09, December, 2011

Published in print edition December, 2011

Currently there have been many armamentaria to be used in cancer treatment. This indeed indicates that the final treatment has not yet been found. It seems this will take a long period of time to achieve. Thus, cancer treatment in general still seems to need new and more effective approaches. The book "Current Cancer Treatment - Novel Beyond Conventional Approaches", consisting of 33 chapters, will help get us physicians as well as patients enlightened with new research and developments in this area. This book is a valuable contribution to this area mentioning various modalities in cancer treatment such as some rare classic treatment approaches: treatment of metastatic liver disease of colorectal origin, radiation treatment of skull and spine chordoma, changing the face of adjuvant therapy for early breast cancer; new therapeutic approaches of old techniques: laser-driven radiation therapy, laser photo-chemotherapy, new approaches targeting androgen receptor and many more emerging techniques.

\title{
How to reference
}

In order to correctly reference this scholarly work, feel free to copy and paste the following:

Ana Catarina Pinto, João Nuno Moreira and Sérgio Simões (2011). Combination Chemotherapy in Cancer: Principles, Evaluation and Drug Delivery Strategies, Current Cancer Treatment - Novel Beyond Conventional Approaches, Prof. Oner Ozdemir (Ed.), ISBN: 978-953-307-397-2, InTech, Available from: http://www.intechopen.com/books/current-cancer-treatment-novel-beyond-conventionalapproaches/combination-chemotherapy-in-cancer-principles-evaluation-and-drug-delivery-strategies

\section{INTECH}

open science | open minds

\section{InTech Europe}

University Campus STeP Ri

Slavka Krautzeka 83/A

51000 Rijeka, Croatia

Phone: +385 (51) 770447

Fax: +385 (51) 686166

www.intechopen.com

\section{InTech China}

Unit 405, Office Block, Hotel Equatorial Shanghai

No.65, Yan An Road (West), Shanghai, 200040, China

中国上海市延安西路65号上海国际贵都大饭店办公楼405单元

Phone: +86-21-62489820

Fax: $+86-21-62489821$ 
(C) 2011 The Author(s). Licensee IntechOpen. This is an open access article distributed under the terms of the Creative Commons Attribution 3.0 License, which permits unrestricted use, distribution, and reproduction in any medium, provided the original work is properly cited. 